ISSN 0103-8478

\title{
Fitorreguladores e posição de explantes foliares na indução à calogênese em cerejeira-do-mato
}

\author{
Phytoregulators and leaf explants position on callus induction in cerejeira-do-mato
}

\author{
Diego Pascoal Golle ${ }^{\mathrm{I}}$ Lia Rejane Silveira Reiniger ${ }^{\mathrm{II}}$
}

\begin{abstract}
O presente trabalho objetivou avaliar o efeito de diferentes formas de inoculação, no meio nutritivo, de explantes foliares de Eugenia involucrata DC., uma espécie florestal nativa com diversas potencialidades econômicas. Foram avaliadas as posições abaxial, adaxial, com e sem cortes no limbo foliar. Foi utilizado o meio de cultura MS acrescido de 10 $\mu M$ de ANA isolado ou das combinações, em $\mu M$, de 2,4-D e BAP: 5-5 e 5-10. A posição dos explantes afeta a calogênese e a organogênese em segmentos foliares de E. involucrata, sendo mais adequada a abaxial sem cortes na região do limbo. A associação dos reguladores de crescimento 2,4-D + BAP na concentração de 5-10 $\mu M$ foi mais promissora para a obtenção de calos, especialmente os nodulares, putativos à embriogênese somática.
\end{abstract}

Palavras-chave: posição de explantes, calos nodulares, organogênese, meios de cultura.

\section{ABSTRACT}

The aim of this research was to evaluate the effect of different forms of leaf explants inoculation in nutritive medium of Eugenia involucrata DC., an native forest species with diverse economic potentials. Inoculations were evaluated at abaxial and adaxial positions, with and without cuts on the leaf surface in the MS nutritive medium supplemented with $10 \mu M$ NAA or combination, in $\mu M$, of 2.4-D and BAP: 5-5 and 5-10. The explants position inoculation affects the callus induction and organogenesis in $\mathbf{E}$. involucrata leaf segments, being the abaxial the most suitable position, without cuts in the leaf surface. The combination of growth regulators 2.4-D and BAP, at concentrations of 5-10( $\mu \mathrm{M})$ was most promising of callus obtaining, especially nodular callus, putative at somatic embryogenesis.

Key words: explants position, nodular callus, organogenesis, culture medium.
Eugenia involucrata DC. (Myrtaceae), conhecida popularmente como cerejeira-do-mato, é uma espécie nativa de vários Estados brasileiros. Possui potencial madeireiro, frutícola, paisagístico, ambiental e medicinal (BACKES \& IRGANG, 2002; PAROUL, 2007). Dotada de sementes recalcitrantes, sua propagação sexuada é dificultada, além de só atingir a idade reprodutiva entre os seis e sete anos de idade (CARVALHO, 2008). Dessa forma, justifica-se a necessidade de estudos relacionados à cultura de tecidos da espécie.

Calos são grupos de células em divisão, obtidas a partir do estímulo fornecido por substâncias presentes no meio nutritivo e por fatores ambientais. Com incitações específicas, processos morfogênicos podem conduzir essas células à formação de embriões somáticos, de brotos e raízes, à propagação em grande escala e a estudos de transformação genética, em que é necessário regenerar as plantas a partir de células isoladas (MA et al., 2009; NEUMANN, et al., 2009; VENTURIERI \& VENTURIERI, 2004). Esse trabalho objetivou avaliar a influência de diferentes formas de inoculação de explantes foliares no meio de cultura e de combinações de fitorreguladores na formação de diferentes tipos de calos em $\boldsymbol{E}$. involucrata.

Os explantes foram isolados a partir de folhas jovens de plantas de quatro anos de idade mantidas em casa de vegetação. Após a

'Laboratório de Cultura de Tecidos Vegetais in vitro, Polo de Inovação Tecnológica do Alto Jacuí, Universidade de Cruz Alta (UNICRUZ), 98020-290, Cruz Alta, RS, Brasil. E-mail: dgolle@unicruz.edu.br. Autor para correspondência.

"Núcleo de Biotecnologia e Melhoramento, Departamento de Fitotecnia, Universidade Federal de Santa Maria (UFSM), Santa Maria, RS, Brasil. 
coleta, as folhas receberam um pré-tratamento de desinfestação, sendo mantidas em solução de Benlate $500^{\circledR}$ (benomyl) a $1 \mathrm{~g} \mathrm{~L}^{-1}+$ sulfato de estreptomicina a $0,1 \mathrm{~g} \mathrm{~L}^{-1}$ por $30 \mathrm{~min}$. Em seguida, foram lavadas com detergente comercial, água corrente $(5 \mathrm{~min})$ e submetidas à sequência: imersão em etanol a $70 \%$ (v/v) por 30s; enxágue em água destilada; imersão em solução de hipoclorito de sódio $(\mathrm{NaOCl})$ a 1,5\% (v/v) com três gotas de detergente comercial por $15 \mathrm{~min}$; e, por fim, triplo enxágue em água destilada estéril.

$\mathrm{O}$ experimento foi conduzido em delineamento inteiramente casualizado, utilizando-se esquema bifatorial $4 \times 3$, em que os níveis do fator " $A$ " corresponderam às posições de inoculação (abaxial e adaxial, com ou sem corte no limbo foliar - seis cortes) dos explantes foliares no meio de cultura, e os níveis do fator " $B$ " às diferentes inserções de reguladores de crescimento no meio, a saber: $10 \mu \mathrm{M}$ de ácido $\alpha$-naftalenoacético (ANA), isoladamente, ou combinações entre ácido 2,4-diclorofenóxiacético (2,4-D) e 6-benzilaminopurina (BAP) nas concentrações 5-5 e 5-10 (em $\mu \mathrm{M})$. Os explantes consistiram de fragmentos foliares de $1 \times 1,5 \mathrm{~cm}$, contendo corte em toda a região de bordadura. Os níveis do fator " $\mathrm{B}$ " foram escolhidos de acordo com resultados observados em experimentos anteriores de indução à calogênese. Utilizaram-se 10 repetições, cada uma composta por um frasco com capacidade para $150 \mathrm{~mL}$, contendo $30 \mathrm{~mL}$ de meio de cultura e dois explantes, totalizando 120 unidades experimentais e 240 explantes. O meio de cultura utilizado foi o MS (MURASHIGE e SKOOG, 1962), contendo 30g L-1 de sacarose, $100 \mathrm{mg} \mathrm{L}^{-1}$ de mio-inositol e $7 \mathrm{~g} \mathrm{~L}^{-1}$ de ágar (pH 5,8). As parcelas permaneceram em sala de cultivo com temperatura de $25 \pm 3^{\circ} \mathrm{C}$ e fotoperíodo de $16 \mathrm{~h}$ (com intensidade luminosa de $20 \mu \mathrm{mol} \mathrm{m} \mathrm{m}^{-2} \mathrm{~s}^{-1}$ ) obtido por meio de lâmpadas fluorescentes "luz do dia". Os frascos permaneceram 45 dias no escuro (em caixas de papel). Após, foram transferidos para a luz por 25 dias adicionais.

Ao final desses 70 dias, foram avaliadas as variáveis: formação de calos, formação de calos rizogênicos, calos friáveis, calos firmes, calos nodulares e oxidação fenólica, todas expressas em porcentagem. Também foram atribuídas notas aos calos, a saber: 0) ausência de formação calogênica; 1) formação de calo cicatricial ou início da formação calogênica; 2) formação calogênica em toda a bordadura (ou nas regiões de cortes); 3) formação calogênica com crescimento secundário; e 4) formação calogênica com crescimento abundante. A normalidade dos erros foi avaliada pelo teste de Kolmogorov-Smirnov e a homocedasticidade pelo teste de Bartlett. Os dados foram submetidos à análise de variância e as médias foram comparadas pelo teste de Tukey a 5\% com auxílio do programa SISVAR versão 4.0 (FERREIRA, 2000).

Para a variável formação de calos, observou-se interação $(\mathrm{P}=0,0030)$ entre os níveis dos fatores testados (Tabela 1). Com a adição de $10 \mu \mathrm{M}$ de ANA, a inoculação dos explantes na posição adaxial com cortes foi significativamente inferior a todas as demais, que não diferiram entre si. Só houve distinções entre as formas de uso dos reguladores de crescimento quando os explantes foram inoculados na posição adaxial com corte. Esse resultado é contrário àquele observado em Platanus occidentalis L. (Platanaceae), em que a inoculação dos explantes na posição adaxial contendo cortes no limbo foliar foi necessária para obtenção de calos e brotações (SUN et al., 2009). Para as notas atribuídas aos calos (Tabela 1), também houve interação $(\mathrm{P}=0,0042)$, em que, com o uso da associação de $5 \mu \mathrm{M}$ de $2,4-\mathrm{D}$ e $10 \mu \mathrm{M}$ de BAP, a inoculação, na posição abaxial sem cortes e adaxial com cortes, favoreceu a formação de calos. Poucos trabalhos com espécies lenhosas relataram a influência da forma de inoculação de explantes no meio nutritivo e a influência desse fator na calogênese. Em Juniperus oxycedrus L. (Cupressaceae), a inoculação, na posição adaxial, dos explantes no meio nutritivo, diferiu dos resultados observados para E. involucrata (GOMEZ \& SEGURA, 1996); já para Litchi chinensis Sonn. (Sapindaceae), houve maior formação de calos quando a face abaxial ficou em contato com o meio nutritivo, semelhante ao observado no presente estudo para E. involucrata (RAHARJO \& LITZ, 2007).

Observaram-se diferenças de acordo com a forma de inoculação dos explantes $(\mathrm{P}=0,0001)$ na formação de calos rizogênicos (Tabela 1), sendo a posição abaxial sem cortes superior às demais. Possivelmente, a forma de contato das células dos tecidos com o meio nutritivo favoreceu essa resposta organogênica para a formação de raízes. Esses dados são díspares em relação aos de PIERIK (1990), que observou aspectos benéficos no aumento da superfície de contato dos explantes com o meio nutritivo por meio de cortes no limbo.

Na formação de calos friáveis (Tabela 1), houve interação $(\mathrm{P}=0,0037)$ entre os fatores, sendo favorável o meio nutritivo contendo 2,4-D e BAP na concentração de 5-10 $(\mu \mathrm{M})$. Esse resultado ocorreu somente na inoculação dos explantes na posição abaxial sem cortes. Já para calos firmes, a forma de introdução dos explantes não interferiu, devendo ser destacado apenas o uso dos fitorreguladores 
Tabela 1 - Efeito da forma de inoculação de explantes foliares de Eugenia involucrata DC. e de diferentes reguladores de crescimento na formação de calos $(\%)$, média de notas atribuídas aos calos; formação de calos rizogênicos (\%); de calos friáveis (\%); de calos nodulares (\%); de calos firmes (\%); e oxidação fenólica (\%) aos 70 dias de cultivo in vitro.

\begin{tabular}{|c|c|c|c|c|}
\hline Fontes de Variação & $10 \mu \mathrm{M}$ ANA & $5 \mu \mathrm{M} 2,4-\mathrm{D}+5 \mu \mathrm{M}$ BAP & $5 \mu \mathrm{M} 2,4-\mathrm{D}+10 \mu \mathrm{M}$ BAP & Média \\
\hline Abaxial Sem Corte & 91,64 a $A^{*}$ & 100,00 a A & 100,00 a $\mathrm{A}$ & 97,21 \\
\hline Abaxial Com Corte & 80,00 a $\mathrm{A}$ & 83,32 a $\mathrm{A}$ & 81,24 a $\mathrm{A}$ & 81,52 \\
\hline Adaxial Sem Corte & 78,55 a $\mathrm{A}$ & 100,00 a $\mathrm{A}$ & 87,77 a $\mathrm{A}$ & 88,77 \\
\hline Adaxial Com Corte & $50,00 \mathrm{~b} \mathrm{~B}$ & 87,50 a $\mathrm{A}$ & 100,00 a $\mathrm{A}$ & 79,17 \\
\hline Média & 75,04 & 92,70 & 92,25 & \\
\hline $\mathrm{CV}(\%)$ & \multicolumn{4}{|l|}{8,39} \\
\hline Fontes de Variação & $10 \mu \mathrm{M}$ ANA & $5 \mu \mathrm{M} 2,4-\mathrm{D}+5 \mu \mathrm{M}$ BAP & dia) - $5 \mu \mathrm{M} 2,4-\mathrm{D}+10 \mu \mathrm{M}$ BAP & Média \\
\hline Abaxial Sem Corte & 1,10 a $\mathrm{B}$ & 1,46 a B & 2,31 a A & 1,62 \\
\hline Abaxial Com Corte & 0,90 a B & 1,75 a A & $1,75 \mathrm{a} \mathrm{b} \mathrm{A}$ & 1,47 \\
\hline Adaxial Sem Corte & 1,00 a B & 1,50 a $\mathrm{A}$ & 1,33 b A B & 1,28 \\
\hline Adaxial Com Corte & 0,69 a $\mathrm{B}$ & 1,54 a A & 2,31 a A & 1,43 \\
\hline Média & 0,92 & 1,56 & 1,86 & \\
\hline $\mathrm{CV}(\%)$ & \multicolumn{4}{|l|}{13,23} \\
\hline Fontes de Variação & $10 \mu \mathrm{M}$ ANA & $5 \mu \mathrm{M} 2,4-\mathrm{D}+5 \mu \mathrm{M}$ BAP & $5 \mu \mathrm{M} 2,4-\mathrm{D}+10 \mu \mathrm{M}$ BAP & Média \\
\hline Abaxial Sem Corte & 16,64 & 7,13 & 16,87 & $13,55 \mathrm{a}$ \\
\hline Abaxial Com Corte & 0,00 & 0,00 & 0,00 & $0,00 \mathrm{~b}$ \\
\hline Adaxial Sem Corte & 14,26 & 0,00 & 0,00 & $4,75 \mathrm{~b}$ \\
\hline Adaxial Com Corte & 0,00 & 0,00 & 0,00 & $0,00 \mathrm{~b}$ \\
\hline Média & 7,72 & 1,78 & 4,22 & \\
\hline $\mathrm{CV}(\%)$ & \multicolumn{4}{|l|}{9,10} \\
\hline Fontes de Variação & $10 \mu \mathrm{M}$ ANA & $5 \mu \mathrm{M} 2,4-\mathrm{D}+5 \mu \mathrm{M}$ BAP & $5 \mu \mathrm{M} 2,4-\mathrm{D}+10 \mu \mathrm{M}$ BAP & Média \\
\hline Abaxial Sem Corte & 0,00 a B & 0,00 a B & 20,00 a A & 6,67 \\
\hline Abaxial Com Corte & 0,00 a $\mathrm{A}$ & 0,00 a $\mathrm{A}$ & $0,00 \mathrm{~b} \mathrm{~A}$ & 0,00 \\
\hline Adaxial Sem Corte & 0,00 a $\mathrm{A}$ & 0,00 a $\mathrm{A}$ & $0,00 \mathrm{~b} \mathrm{~A}$ & 0,00 \\
\hline Adaxial Com Corte & 0,00 a $\mathrm{A}$ & 0,00 a $\mathrm{A}$ & $0,00 \mathrm{~b} \mathrm{~A}$ & 0,00 \\
\hline Média & 0,00 & 0,00 & 5,00 & \\
\hline CV $(\%)$ & \multicolumn{4}{|l|}{7,57} \\
\hline Fontes de Variação & $10 \mu \mathrm{M}$ ANA & $5 \mu \mathrm{M} 2,4-\mathrm{D}+5 \mu \mathrm{M}$ BAP & $5 \mu \mathrm{M} 2,4-\mathrm{D}+10 \mu \mathrm{M}$ BAP & Média \\
\hline Abaxial Sem Corte & 0,00 & 30,00 & 25,00 & 18,33 \\
\hline Abaxial Com Corte & 0,00 & 5,00 & 10,00 & 5,00 \\
\hline Adaxial Sem Corte & 0,00 & 20,00 & 35,00 & 10,00 \\
\hline Adaxial Com Corte & 5,00 & 0,00 & 25,00 & 18,33 \\
\hline Média & $1,25 \mathrm{~B}$ & 13,75 A B & $23,75 \mathrm{~A}$ & \\
\hline $\mathrm{CV}(\%)$ & \multicolumn{4}{|l|}{18,08} \\
\hline Fontes de Variação & $10 \mu \mathrm{M}$ ANA & $5 \mu \mathrm{M} 2,4-\mathrm{D}+5 \mu \mathrm{M}$ BAP & $5 \mu \mathrm{M} 2,4-\mathrm{D}+10 \mu \mathrm{M}$ BAP & Média \\
\hline Abaxial Sem Corte & 25,00 & 0,00 & 40,00 & 21,67 \\
\hline Abaxial Com Corte & 5,00 & 20,00 & 15,00 & 13,33 \\
\hline Adaxial Sem Corte & 5,00 & 30,00 & 25,00 & 20,00 \\
\hline Adaxial Com Corte & 10,00 & 10,00 & 40,00 & 20,00 \\
\hline Média & $11,25 \mathrm{~B}$ & $15,00 \mathrm{~A} \mathrm{~B}$ & $30,00 \mathrm{~A}$ & \\
\hline CV $(\%)$ & \multicolumn{4}{|l|}{20,30} \\
\hline Fontes de Variação & $10 \mu \mathrm{M}$ ANA & $5 \mu \mathrm{M} 2,4-\mathrm{D}+5 \mu \mathrm{M}$ BAP & \%)--- $5 \mu \mathrm{M} 2,4-\mathrm{D}+10 \mu \mathrm{M}$ BAP & Média \\
\hline Abaxial Sem Corte & 16,64 a $\mathrm{A}$ & 75,71 a B & 100,00 a B & 64,12 \\
\hline Abaxial Com Corte & $70,00 \mathrm{~b} \mathrm{~A}$ & 100,00 a B & 81,24 a A B & 83,74 \\
\hline Adaxial Sem Corte & 14,26 a A & 100,00 a B & 100,00 a B & 71,42 \\
\hline Adaxial Com Corte & $50,00 \mathrm{~b} \mathrm{~A}$ & $87,5 \mathrm{aB}$ & 94,44 a B & 73,31 \\
\hline Média & 37,73 & 90,80 & 92,92 & \\
\hline $\mathrm{CV}(\%)$ & 10,88 & & & \\
\hline
\end{tabular}

* Médias seguidas pela mesma letra maiúscula na linha e minúscula na coluna não diferem entre si pelo teste de Tukey em nível de 5 \% de probabilidade de erro. A letra "a" foi atribuída à melhor resposta para cultivo in vitro.

Ciência Rural, v.43, n.10, out, 2013. 
( $\mathrm{P}=0,0168)$, em que a média da combinação $5 \mu \mathrm{M}$ de $2,4-\mathrm{D}+10 \mu \mathrm{M}$ de BAP foi superior a $10 \mu \mathrm{M}$ de ANA, mas que não diferiu da combinação $5 \mu \mathrm{M}$ de 2,4-D $+5 \mu \mathrm{M}$ de BAP. A formação de calos nodulares, por sua vez, foi afetada apenas pelos diferentes usos de fitorreguladores $(\mathrm{P}=0,0006)$. Esses calos, putativos à embriogênese, tiveram sua maior ocorrência com o uso das combinações de 2,4-D e BAP na concentração, em $\mu \mathrm{M}$, de 5-10. A oxidação fenólica apresentou interação significativa $(\mathrm{P}=0,0001)$ entre os níveis dos fatores (Tabela 1). Houve redução nas taxas oxidativas dos explantes sem cortes quando se utilizou o fitorregulador ANA, corroborando os registros de ANDRADE et al. (2000) e LEDO et al. (2002), que relatam o aumento no índice de fenóis devido às injúrias. Além disso, sabe-se que a atividade da fenilalanina amoniliase (PAL), enzima que atua no metabolismo de compostos fenólicos, é aumentada pela agressão aos tecidos (TAIZ \& ZEIGER, 2009).

A melhor forma de inoculação de explantes foliares no meio nutritivo é na posição abaxial em contato com o meio, sem cortes no limbo foliar, o que favorece a obtenção de diversos tipos de calos em $\boldsymbol{E}$. involucrata, e o uso da combinação de 2,4-D e BAP 5-10 favorece o surgimento de calos putativos à embriogênese somática.

\section{REFERÊNCIAS}

ANDRADE, M.W. et al. Micropropagação de aroeira (Myracrodruon urundeuva Fr. Allemao). Ciência e Agrotecnologia, Lavras, v.24, n.1, p.174 - 180, 2000.

BACKES, A.; IRGANG, B. Árvores do Sul: guia de identificação e interesse ecológico. Porto Alegre: Pallotti, 2002. 275p.

CARVALHO, P.E. Espécies arbóreas brasileiras. Brasília: Embrapa Informação Tecnológicas; Colombo: Embrapa Florestas, 2008. v.3, 593p.

FERREIRA, D.F. Análises estatísticas por meio do Sisvar para Windows versão 4.0. In: REUNIÃO ANUAL DA REGIÃO BRASILEIRA DA SOCIEDADE INTERNACIONAL DE BIOMETRIA, 45., 2000, São Carlos, SP. Anais... São Carlos: Universidade Federal de São Carlos, 2000. p.255-258.

GOMEZ, M.P.; SEGURA, J. Morphogenesis in leaf and singlecell cultures of mature Juniperus oxycedrus. Tree Physiology, Victoria, v.16, n.8, p.681-686, 1996. Disponível em: <http:// treephys.oxfordjournals.org/content/16/8/681.full.pdf>. Acesso em: 23 jul. 2012. doi:10.1093/treephys/15.9.625.

LEDO,A.S. etal. Explantes de cupuaçuzeiro submetidos a diferentes condições de cultura in vitro. Revista Brasileira de Fruticultura, Jaboticabal, v.24, n.3, p.604-607, 2002. Disponível em: <http:// dx.doi.org/10.1590/S0100-29452002000300005>. Acesso em: 16 abr. 2012. doi:10.1590/S0100-29452002000300005.

MA, X.Y. et al. Leaf callus induction and suspension culture establishment in lychee (Litchi chinensis Sonn.) cv. 'Huaizhi'. Acta Physiologiae Plantarum, Kraków, v.31, n.2, p.401-405, 2009. Disponível em: <http://dx.doi.org/ 10.1007/s11738-008-0223-x.> Acesso em: 22 ago. 2012. doi: 10.1007/s11738-008-0223-x.

MURASHIGE, T.; SKOOG, F. A revised medium for rapid growth and bio assays with tobacco tissue cultures. Physiologia Plantarum, Copenhagen, v.15, p.473-49, 1962.

NEUMANN, K.H. et al. Plant cell and tissue culture - a toll in biotechnology: basics and application. Berlin: Springer Verlang, 2009. 333p.

PAROUL, N. et al. Avaliação da composição química do óleo volátil de cerejeira (Eugenia involucrata DC). In: REUNIÃO ANUAL DA SOCIEDADE BRASILEIRA DE QUÍMICA, 30., 2007, Águas de Lindóia. Anais... Águas de Lindóia: Sociedade Brasileira de Química, 2007. p.1-1. Disponível em: <http://sec.sbq.org.br/ cdrom/30ra/resumos/T1853-1.pdf $>$. Acesso em: 23 mar. 2011.

PIERIK, R.L.M. Cultivo in vitro de las plantas superiores. Madrid: Mundi-Prensa, 1990. 326p.

RAHARJO, S.H.T.; LITZ, R.E. Somatic embryogenesis and plant regeneration of litchi (Litchi chinensis Sonn.) from leaves of mature phase trees. Plant Cell, Tissue and Organ Culture, Dordrecht, v.89, n.2-3, p.113-119, 2007. Disponível em: <http:// www.springerlink.com/content $/ 64185 \mathrm{kp} 7047052 \mathrm{mp} />$. Acesso em: 28 ago. 2012. doi: 10.1007/s11240-007-9219-2.

SUN, Y. et al. Adventitious bud regeneration from leaf explants of Platanus occidetalis L. ande genetic stability assessment. Acta Physiologiae Plantarum, Kraków, v.31, n.1, p.33-41, 2009. Disponível em: <http://dx.doi.org/ DOI: 10.1007/s11738-0080196-9>. Acesso em: 13 jul. 2012. doi: DOI: 10.1007/s11738008-0196-9.

TAIZ, L.; ZEIGER, E. Fisiologia vegetal. 4ed. Porto Alegre: Artmed, 2009. 819p.

VENTURIERI, G.A.; VENTURIERI, G.C. Calogênese do híbrido Theobroma grandiflorum x T. obovatum (Sterculiaceae). Acta Amazônica, Manaus, v.34, n.4, p.507-511, 2004. Disponível em: $<$ http://www.scielo.br/scielo.php?script=sci_arttext\&pid $=$ S0044-59672004000400004 $>$ $>$ Acesso em: 16 jul. 2012. doi: 10.1590/S0044-59672004000400004. 